\title{
Special Issue: Jets, Wakes, and Separated Flows
}

\section{Ephraim Gutmark $^{1} \cdot$ Toshihiko Shakouchi $^{2} \cdot$ Mihai Mihaescu $^{3}$}

Published online: 11 April 2019

(C) Springer Nature B.V. 2019

The Sixth International Conference on Jets, Wakes, and Separated Flows (ICJWSF17), was held at the University of Cincinnati, Ohio, USA in October 9-12, 2017. This special issue contains 14 papers selected from a total of 80 papers presented during the ICJWSF17 Conference. The conference goal was to give scientists, engineers and students from the US and other countries an opportunity to discuss research on jets, wakes, and separated flows, topics that are of significant importance and interest in the field of fluid mechanics, with impact on diverse fields of engineering such as aeroacoustics, combustion, heat transfer, multiphase flows, and turbomachinery. The conference aims to promote exchange of information on advances in the field, and to spawn collaborative research between the participants. This special issue of Flow Turbulence and Combustion is the first to include selected papers from this conference. The papers were selected and reviewed on the basis of their quality as judged by the reviewers in relation to the aims and scope of the Journal.

All papers published in this Special Issue were subjected to the same rigorous peer- review process as normal submissions to the Journal. It was therefore independent from the review of the conference submissions, which was used only in order to select the authors that were invited to submit a paper for this volume. The Guest Editors are grateful for the opportunity to publish this volume, which makes a substantial contribution to advancing the field of fluid mechanics.

Ephraim Gutmark

ephraim.gutmark@uc.edu

Toshihiko Shakouchi

shako@mach.mie-u.ac.jp

Mihai Mihaescu

mihai@mech.kth.se

Department of Aerospace Engineering and Engineering Mechanics, University of Cincinnati, Cincinnati, OH, USA

2 Department of Mechanical Engineering, Mie University, Tsu, Japan

3 Department of Mechanics, KTH Royal Institute of Technology, Stockholm, Sweden 